\title{
Hypoxia stimulates the cytoplasmic localization of oncogenic long noncoding RNA LINC00152 in colorectal cancer
}

\author{
YUJIRO NISHIZAWA ${ }^{1,2}$, MASAMITSU KONNO ${ }^{2,3}$, AYUMU ASAI ${ }^{2,3}$, JUN KOSEKI ${ }^{3}$, KOICHI KAWAMOTO ${ }^{1,2}$, \\ NORIKATSU MIYOSHI ${ }^{1}$, HIDEKAZU TAKAHASHI ${ }^{1}$, NAOHIRO NISHIDA ${ }^{1}$, NAOTSUGU HARAGUCHI ${ }^{1}$, \\ DAISUKE SAKAI ${ }^{2}$, TOSHIHIRO KUDO ${ }^{2}$, TAISHI HATA ${ }^{1}$, CHU MATSUDA $^{1}$, TSUNEKAZU MIZUSHIMA ${ }^{1,4}$, \\ TAROH SATOH ${ }^{2}$, YUICHIRO DOKI ${ }^{1}$, MASAKI MORI ${ }^{1}$ and HIDESHI ISHII $^{2,3}$ \\ Departments of ${ }^{1}$ Gastroenterological Surgery, ${ }^{2}$ Frontier Science for Cancer and Chemotherapy, \\ ${ }^{3}$ Disease Data Science, ${ }^{4}$ Therapeutics for Inflammatory Bowel Diseases, \\ Graduate School of Medicine, Osaka University, Suita, Osaka 565-0871, Japan
}

Received September 19, 2017; Accepted October 19, 2017

DOI: 10.3892/ijo.2017.4218

\begin{abstract}
Recent studies have indicated that long noncoding RNAs (lncRNAs) play a pivotal role in almost all physiological cellular processes, including every stage of cancer development. Given that hypoxia in the tumor microenvironment is involved in the malignant behavior of tumors, such as invasion and metastasis, we investigated the cytoplasmic and nuclear localization of lncRNAs in colorectal cancer cells. A cell culture under hypoxic conditions revealed several lncRNAs, such as LINC00152, whose levels were increased in the cytoplasm of colorectal cancer cells. A database study indicated that LINC00152 shares microRNA-binding sites, such as miR-138 and miR-193, with the hypoxia-inducible factor 1 (HIF1), thus suggesting that LINC00152 could possibly function as a competing endogenous RNA that can augment Hif 1 translation in the cytoplasm of hypoxic colorectal cancer cells. Moreover, the data presented in the studies of surgically resected samples showed that patients with colorectal cancer exhibiting high LINC00152 expression were associated with a worsened survival rate; this supports the suggested oncogenic function of LINC00152 in the cytoplasm under hypoxic conditions. The present study demonstrated that lncRNA networks could provide diagnostic tools and novel therapeutic targets against colorectal cancer cells.
\end{abstract}

Correspondence to: Dr Hideshi Ishii, Department of Medical Data Science, Graduate School of Medicine, Osaka University, Yamadaoka 2-2, Suita, Osaka 565-0871, Japan

E-mail: hishii@gesurg.med.osaka-u.ac.jp

Dr Masaki Mori, Department of Gastroenterological Surgery, Graduate School of Medicine, Osaka University, Yamadaoka 2-2, Suita, Osaka 565-0871, Japan

E-mail: mmori@gesurg.med.osaka-u.ac.jp

Key words: lncRNA, LINC00152, hypoxia, miRNA, colorectal cancer, survival

\section{Introduction}

Globally, colorectal cancer (CRC) is the third most common cancer in men $(746,000$ cases annually, $10.0 \%$ of total cancers) and the second in women $(614,000$ cases, $9.2 \%$ of total cancers) (1). The early stages of CRC can be detected by occult blood examination in stool samples or endoscopic examination. Subsequently, CRC can be treated with surgery and chemotherapy, which have been shown to increase patient survival. However, advanced cases exhibiting metastasis to distant organs are associated with worsened survival rates, indicating the rationale for further study of the underlying mechanisms of CRC (1).

Although cancer is a genetic disease, epigenetic alterations also play a pivotal role in cancer development; eventually, the hypoxic responses within the tumor microenvironment characterize the malignant behavior of tumors as a hallmark of cancer $(2,3)$. Indeed, recent advances in the high-throughput, next generation sequence technology have aided in the identification and characterization of long noncoding RNA (lncRNA), which is a type of noncoding RNA (ncRNA) exceeding 200 nucleotides in length, and epigenetic alterations, which are defined as mechanisms leading to changes in gene expression related to cellular biology and tissue homeostasis but not involving changes in the DNA sequence (4). HOX transcript antisense RNA (HOTAIR), a human gene located on chromosome 12 , is the first example of IncRNA expressed on one chromosome and influencing transcription on another chromosome (5). HOTAIR mediates the trimethylation of histone $\mathrm{H} 3$ at lysine 27 and demethylation of histone $\mathrm{H} 3$ at dimethyl lysine 4 via the recruitment of polycomb repressive complex 2 and lysine-specific demethylase 1/co-repressor of RE1-silencing transcription factor (coREST)/REST complex to target gene promoters. The recruitment of these factors leads to gene silencing in the nucleus of cancer cells in gastrointestinal and lung tumors, which is associated with patient prognosis (6). Subsequently, numerous studies have indicated that not only mutations or altered expression of mRNA or protein-coding genes but also mutations and deregulation of ncRNAs, particularly lncRNA, play major roles in cancer 
development (7). It has been reported that several other lncRNAs, including MALAT1, CCAT2, SPRY4-IT1, RSU1P2, CCHE1, lncRNA-EBIC and plasmacytoma variant translocation 1 (PVT1), are also involved in cancer (8). Moreover, PVT1, a newly discovered lncRNA, is a potential biomarker for clinicopathological characteristics of different types of cancer (9). Recent studies indicate roles of lincRNAs in CRC (Table I). In cancer, IncRNAs are involved in the biological behavior of tumors, altering cancer cell localization and turnover (10). Although multiple lncRNAs are involved in the biological processes within the nucleus, and recent studies have indicated that IncRNAs, such as Xist, nuclear-enriched abundant transcript 1 (NEAT1), MALAT1 and TERRA, are involved in various nuclear functions, the differential roles of lncRNAs in the cytoplasm and nucleus remains poorly understood (11).

In contrast to the epigenetic control of lncRNAs, which bind to histone-modifying enzymes in case of HOTAIR, little is known regarding the cytoplasmic involvement of lncRNAs. Recent studies indicated that a small fraction of ncRNAs, such as microRNAs, functions as competitive endogenous RNA (ceRNA). In the context of ceRNA, some pseudogene RNAs can act as 'sponges' through the competitive binding of common miRNA, thereby attenuating repression via the sequestration of miRNAs from the parental mRNA (12). Because ceRNAs include all transcripts, such as mRNA, tRNA, rRNA, lncRNA, pseudogene RNA and circular RNA, all of which may become targets of miRNA depending on the spatiotemporal situation, it is suggested that lncRNAs may function as a 'sponge' and that a competitive balance may exist between ncRNAs and the target mRNA (12).

In the tumor microenvironment, several processes within the transcriptional networks of p53 and hypoxia-inducible factor $1 \alpha(H I F 1 \alpha)$ are modulated by hypoxia (13), and defines hypoxic glycolysis metabolism in normoxia, which characterizes cancer cells, as the so-called Warburg effect, cancer metabolism (14).

In the present study, we analyzed the expression of IncRNA under normoxic and hypoxic conditions and found that oncogenic long intergenic noncoding RNA 152 (LINC00152) expression is increased in the cytoplasm during hypoxia in CRC cells. A sequence data study indicated that LINC00152 shares the microRNA-binding sites miR-138 and miR-193, which are located in the peptide-coding mRNA of the HIF1 gene. A study of clinical samples further supported the significance of LINC00152.

\section{Materials and methods}

Cell lines and cell culture. The human CRC cell line HCT-116 was purchased from the American Type Culture Collection (Manassas, VA, USA) and maintained in Dulbecco's modified Eagle's medium (Sigma-Aldrich, St. Louis, MO, USA) supplemented with $10 \%$ fetal bovine serum (FBS) at $37^{\circ} \mathrm{C}$ under $5 \% \mathrm{CO}_{2}$ in a humidified incubator.

Separation of nuclear and cytoplasmic fractions. To separate the total cellular fractions into nuclear and cytoplasmic fractions, we used a PARIS kit (AM1921; Thermo Fisher Scientific, Yokohama, Japan) according to the manufacturer's protocol. This kit enables the isolation of both RNA and protein from the same experimental sample and also permits the separation of nuclear and cytoplasmic fractions prior to RNA and/or protein isolation.

Polymerase chain reaction (PCR) array of IncRNA. We performed an IncRNA PCR array using a Human Cancer PathwayFinder RT ${ }^{2}$ IncRNA PCR array (LAHS-002Z; Qiagen, Hilden, Germany) according to the protocol detailed in the $\mathrm{RT}^{2}$ Profiler PCR array Handbook. This array profiles the expression of 84 lncRNAs that are differentially expressed in tumors compared with normal tissue. Briefly, total RNA was extracted from cultured cells using TRIzol ${ }^{\circledR}$ RNA isolation reagents (Thermo Fisher Scientific) as previously described (15). The RNA from each fraction was extracted using a PARIS kit.cDNA was synthesized from 500 ng of RNA using an RT ${ }^{2}$ First Strand kit (Qiagen) according to the manufacturer's protocol. PCR was performed in an Applied Biosystems 7900 HT Fast Real-Time PCR system (Applied Biosystems, CA, USA) using the Thunderbird ${ }^{\circledR}$ SYBR ${ }^{\circledR}$ qPCR mix (Toyobo Life Science, Osaka, Japan). The cycling conditions consisted of $95^{\circ} \mathrm{C}$ for $10 \mathrm{~min}$, 40 cycles of $95^{\circ} \mathrm{C}$ for $15 \mathrm{sec}$, and $60^{\circ} \mathrm{C}$ for $1 \mathrm{~min}$.

Real-time quantitative reverse transcriptase-PCR ( $q R T-P C R)$. Total RNA was extracted from the cultured cells using TRIzol ${ }^{\circledR}$ RNA isolation reagents. cDNA was synthesized from $1 \mu \mathrm{g}$ of the total RNA using a High Capacity RNA-to-cDNA kit (Thermo Fisher Scientific) according to the manufacturer's protocol. PCR was performed in a Light Cycler ${ }^{\mathrm{TM}} 2.0$ system (Roche Applied Science, Tokyo, Japan) using the Thunderbird ${ }^{\circledR}$ $\mathrm{SYBR}^{\circledR}$ qPCR mix. The expression level was calculated using the $\Delta \Delta \mathrm{Cq}$ method (16). The calculated values were then normalized against the expression of glyceraldehyde 3-phosphate dehydrogenase (GAPDH) or RPLP0 for mRNA. The PCR reaction mixture consisted of $5 \mu \mathrm{l}$ of $1 / 100 \mathrm{cDNA}, 10.0 \mu \mathrm{l}$ of Thunderbird ${ }^{\mathrm{TM}} \mathrm{SYBR}^{\circledR}$ qPCR mix, $4.0 \mu \mathrm{l}$ of water, and $0.5 \mu \mathrm{l}$ of each primer. The amplification protocol consisted of 40 cycles of denaturation at $95^{\circ} \mathrm{C}$ for $15 \mathrm{sec}$, annealing at $60^{\circ} \mathrm{C}$ for $1 \mathrm{~min}$, and extension at $72^{\circ} \mathrm{C}$ for $30 \mathrm{sec}$.

The following primers were used: $C A 9,5$ '-CTAGAGGCT GGATCTTGGAGAA-3' (forward) and 5'-CTTGGCAGTTAA AAGGAAGTGG-3' (reverse); LINC00152, 5'-CTCCAGCAC CTCTACCTGTTG-3' (forward) and 5'-GGACAAGGGATT AAGACACACA-3' (reverse); GAPDH, 5'-AGCCACATCGCT CAGACAC-3' (forward) and 5'-GCCCAATACGACCAAA TCC-3' (reverse); RPLP0, 5'-AGCCACATCGCTCAGACAC-3' (forward) and 5'-GCCCAATACGACCAAATCC-3' (reverse).

Statistical analysis. Statistically significant differences were determined by a Student's t-test and Fisher's exact probability test as appropriate. JMP ${ }^{\circledR}$ Pro12 (SAS Institute Inc., Cary, $\mathrm{NC}$, USA) was used for all statistical analyses. The data are reported as the mean \pm SEM. Results were considered statistically significant when P-value of $<0.05$ was obtained.

\section{Results}

Identification of hypoxia-regulated lncRNA. We performed an IncRNA PCR array using the total RNA of HCT-116 cells incubated for $72 \mathrm{~h}$ under conditions of hypoxia $\left(1 \% \mathrm{O}_{2}\right)$ or normoxia $\left(20 \% \mathrm{O}_{2}\right)$ (Fig. 1A). As a preliminary experiment, we 
Table I. LncRNAs associated with CRC.

\begin{tabular}{|c|c|c|c|c|c|}
\hline LncRNA & Name & Function & Expression & Mechanism & Refs. \\
\hline LINC-PINT & $\begin{array}{l}\text { Long intergenic } \\
\text { non-protein coding RNA, } \\
\text { p53 induced transcript }\end{array}$ & $\begin{array}{l}\text { Inhibits cell proliferation } \\
\text { and promotes apoptosis }\end{array}$ & Downregulated & $\begin{array}{l}\text { Interacts with the polycomb } \\
\text { repressive complex } 2 \text { (PRC2) } \\
\text { to silence gene targets }\end{array}$ & 26 \\
\hline PR-lncRNA-1 & p53-regulated lncRNA-1 & $\begin{array}{l}\text { Inhibits cell proliferation, } \\
\text { and promotes apoptosis }\end{array}$ & Downregulated & $\begin{array}{l}\text { Enhances p53 } \\
\text { transcriptional activation }\end{array}$ & 27 \\
\hline MALAT1 & $\begin{array}{l}\text { Metastasis associated } \\
\text { lung adenocarcinoma } \\
\text { transcript } 1\end{array}$ & $\begin{array}{l}\text { Promotes cell } \\
\text { proliferation } \\
\text { and metastasis }\end{array}$ & Overexpressed & $\begin{array}{l}\text { Related to alternative } \\
\text { splicing and active } \\
\text { transcription }\end{array}$ & 28 \\
\hline PTENP1 & $\begin{array}{l}\text { Phosphatase and tensin } \\
\text { homolog pseudogene } 1\end{array}$ & $\begin{array}{l}\text { Inhibits cell proliferation, } \\
\text { migration, invasion } \\
\text { and tumor growth }\end{array}$ & $\begin{array}{l}\text { Locus selectively } \\
\text { lost in sporadic } \\
\text { colon cancer }\end{array}$ & $\begin{array}{l}\text { Decoy for microRNAs } \\
\text { that target PTEN }\end{array}$ & 29 \\
\hline CCAT2 & $\begin{array}{l}\text { Colon cancer associated } \\
\text { transcript } 2\end{array}$ & $\begin{array}{l}\text { Promotes tumor } \\
\text { growth, metastasis, } \\
\text { chromosomal instability }\end{array}$ & Overexpressed & $\begin{array}{l}\text { Enhancement of WNT } \\
\text { signaling activity }\end{array}$ & 30 \\
\hline HOTAIR & $\begin{array}{l}\text { Hox antisense } \\
\text { intergenic RNA }\end{array}$ & $\begin{array}{l}\text { Cancer progression } \\
\text { by remodeling } \\
\text { the chromatin landscape }\end{array}$ & Overexpressed & $\begin{array}{l}\text { Modular scaffold by } \\
\text { interacting with PRC2 }\end{array}$ & 31 \\
\hline LINC00152 & NA & ceRNA is suggested & Overexpressed & Hypoxia pathway & Present \\
\hline
\end{tabular}

NA, not applicable.
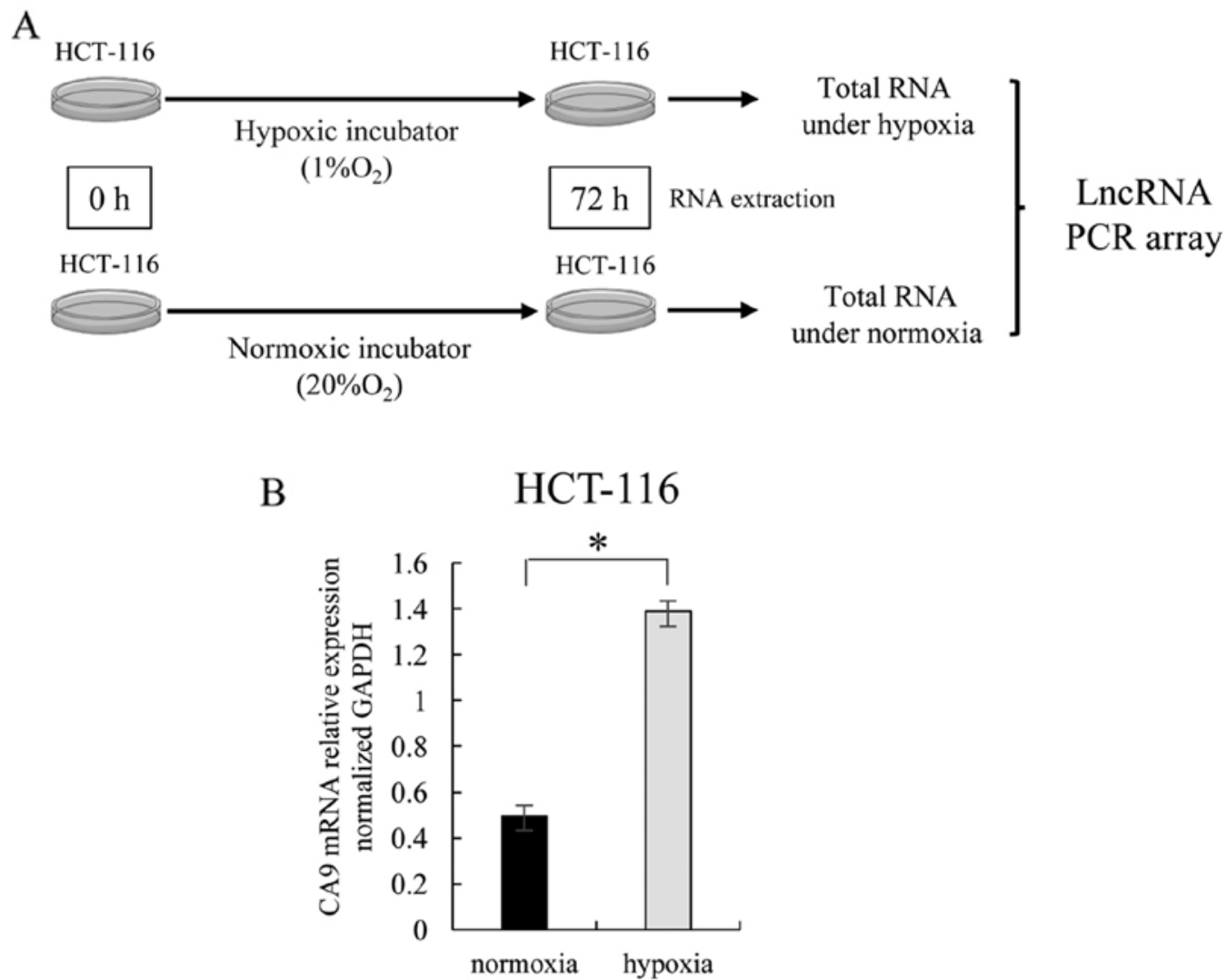

Figure 1. Hypoxia-induced long noncoding RNAs (lncRNAs). (A) Overview of lncRNA PCR array for total RNA. HCT-116 cell lines were used and were incubated under hypoxic or normoxic conditions for $72 \mathrm{~h}$. Total RNA was extracted and used for lncRNA PCR array. (B) CA9 mRNA relative expression normalized to glyceraldehyde 3-phosphate dehydrogenase (GAPDH) is shown as based on qRT-PCR analysis using HCT-116 cells cultured under normoxic or hypoxic condition. ${ }^{*} \mathrm{P}<0.05$. 
A
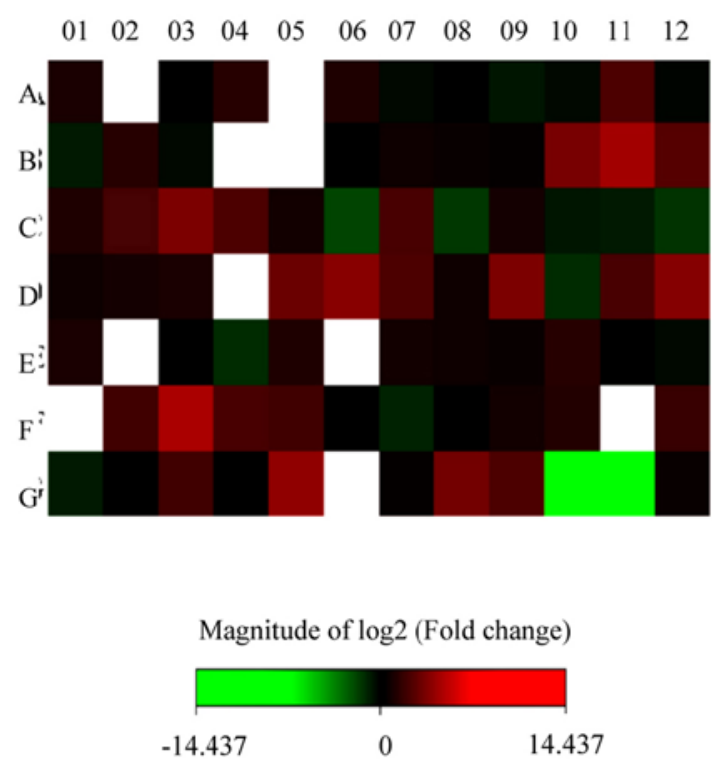

B

\author{
Upregulated lncRNAs \\ under hypoxia \\ (Fold Change $>1.5$ )
}

\begin{tabular}{|c|c|}
\hline TRERNAl & 49.10020014 \\
\hline DLX6-AS1 & 39.91206448 \\
\hline PCGEM1 & 28.19444424 \\
\hline H19 & 22.34701142 \\
\hline LINC00538 & 13.88862623 \\
\hline LUCAT1 & 13.08865548 \\
\hline HIF1A-AS2 & 11.56606332 \\
\hline MIR7-3HG & 11.35837072 \\
\hline $\begin{array}{l}\text { ADAMTS9- } \\
\text { AS2 }\end{array}$ & 6.070435413 \\
\hline SNORA73A & 5.677536202 \\
\hline LINC00887 & 4.963507595 \\
\hline UCA1 & 4.912461157 \\
\hline HNF1A-AS1 & 4.902572618 \\
\hline POU5F1P5 & 4.609946475 \\
\hline SUMO1P3 & 3.949590281 \\
\hline PCAT1 & 3.720459979 \\
\hline PRNCR1 & 3.686096908 \\
\hline NEAT1 & 2.45866129 \\
\hline DGCR5 & 2.300797479 \\
\hline RMRP & 2.227306344 \\
\hline MIR31HG & 2.064974548 \\
\hline HEIH & 1.99780116 \\
\hline ACTA2-AS1 & 1.913392701 \\
\hline LINC01233 & 1.824662956 \\
\hline LINC00152 & 1.822229916 \\
\hline MALAT1 & 1.818479926 \\
\hline PVT1 & 1.641808658 \\
\hline HOTAIR & 1.622198089 \\
\hline MRPL23-AS1 & 1.616003138 \\
\hline LSINCT5 & 1.577504368 \\
\hline
\end{tabular}

C
Downregulated lncRNAs under hypoxia
(Fold Change $<0.67$ )

\begin{tabular}{l|l}
\hline IPW & 0.550510505 \\
\hline SNHG16 & 0.540176581 \\
\hline CRNDE & 0.521283102 \\
\hline PTCSC3 & 0.462776015 \\
\hline PTCSC1 & 0.445060386 \\
\hline CBR3-AS1 & 0.443596535 \\
\hline LINC01234 & 0.405111235 \\
\hline MIR17HG & 0.396200608 \\
\hline B2M & 0.379720028 \\
\hline TUSC7 & 0.347495211 \\
\hline HOXA11-AS & 0.306865423 \\
\hline PTENP1 & 0.298238208 \\
\hline HOXA-AS2 & 0.286438635 \\
\hline HOTAIRM1 & 0.245930061 \\
\hline JADRR & 0.202904111 \\
\hline HULC & 0.027525489 \\
\hline
\end{tabular}

Figure 2. Results of the hypoxia-induced lncRNA PCR array. (A) Heat map showing the expression of 84 long noncoding RNAs (lncRNAs). The fold-change in expression was determined under hypoxic/normoxic condition; IncRNAs with red background more expressed under hypoxic than normoxic condition, which indicates upregulated expression of lncRNAs under hypoxic conditions (B). In contrast, lncRNAs with green background more expressed under normoxic than hypoxic condition, which indicated downregulated expression of lncRNAs under hypoxic condition (C). Data of 10 lncRNAs with a white background are lacking. (B) Upregulated lncRNAs under hypoxic conditions. Thirty lncRNAs with a fold-change of $>1.5$ were determined to be significantly upregulated. Some IncRNAs with '*' were previously reported to be upregulated under hypoxic condition. (C) Downregulated lncRNAs under hypoxic conditions. Sixteen IncRNAs with a fold-change of $<0.67$ were determined to be significantly downregulated.

assessed the level of carbonic anhydrase 9 (CA9) expression, which is known to be an indicator of hypoxia (17). CA9 expression was significantly higher in HCT-116 cells incubated under hypoxic conditions than in those incubated under normoxic conditions (Fig. 1B). We validated that the hypoxic environment had been reproduced by the hypoxic incubator. Next we performed study of IncRNA expression using the Human Cancer PathwayFinder RT ${ }^{2}$ lncRNA PCR array, which included 84 sets of primers for lncRNAs (Fig. 2A). The lncRNA PCR array revealed that $30 \mathrm{lncRNAs}$ were upregulated (Fig. 2B) and 16 lncRNAs were downregulated (Fig. 2C) under hypoxic conditions compared with normoxic conditions. Among the lncRNAs upregulated under hypoxic conditions, some were previously reported to be upregulated due to hypoxia (18).

Identification of IncRNAs that are downregulated in the nucleus and upregulated in the cytoplasm under hypoxic conditions. We performed an lncRNA PCR array using nuclear or cytoplasmic RNA of HCT-116 cells incubated for $72 \mathrm{~h}$ under conditions of hypoxia $\left(1 \% \mathrm{O}_{2}\right)$ or normoxia $\left(20 \% \mathrm{O}_{2}\right)$ (Fig. 3A). As a preliminary experiment, we determined the level of
NEAT1 expression, which is known to be a nuclear lncRNA. This preliminary experiment demonstrated that NEAT1 was mainly expressed in the nucleus (Fig. 3B), which indicated adequate separation of the total fraction into nuclear and cytoplasmic fractions. Fig. 4A shows the results of the lncRNA PCR array of the nucleus, and Fig. 4B shows the results of the IncRNA PCR array of the cytoplasm. We focused on the lncRNAs that were downregulated in the nucleus and upregulated in the cytoplasm under hypoxic conditions because they may function as ceRNAs. The PCR array revealed that, under hypoxic conditions, nine lncRNAs were upregulated in the cytoplasm, 46 were downregulated in the nucleus, and five were downregulated in the nucleus but upregulated in the cytoplasm (Fig. 5A). Interestingly, these five lncRNAs were included in the 30 lncRNAs that were upregulated under hypoxic conditions compared with normoxic conditions (Fig. 2B).

LINC00152 is associated with poor prognosis in colorectal cancer. To validate the expression of the five IncRNAs that were downregulated in the nucleus and upregulated in the 
A

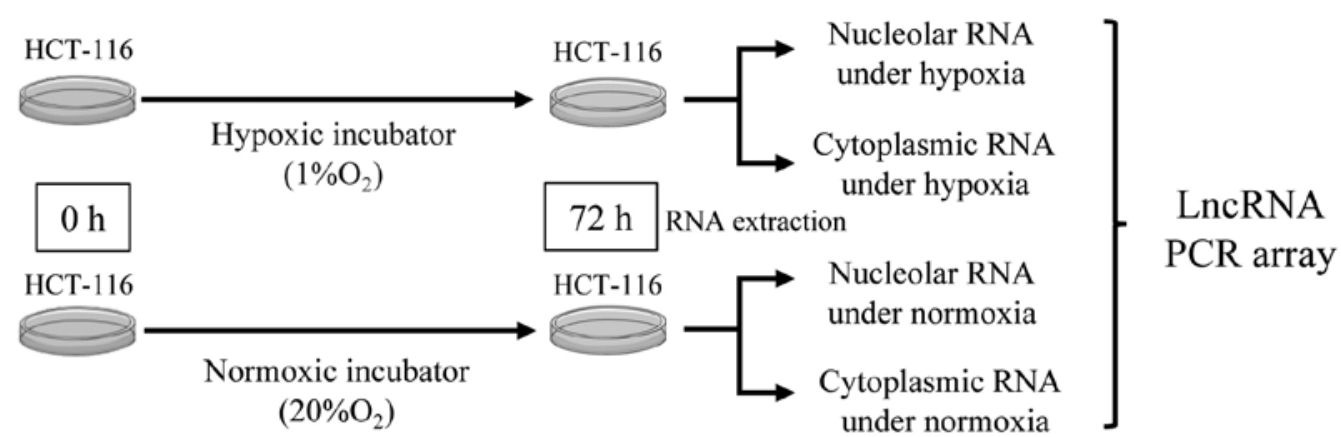

B

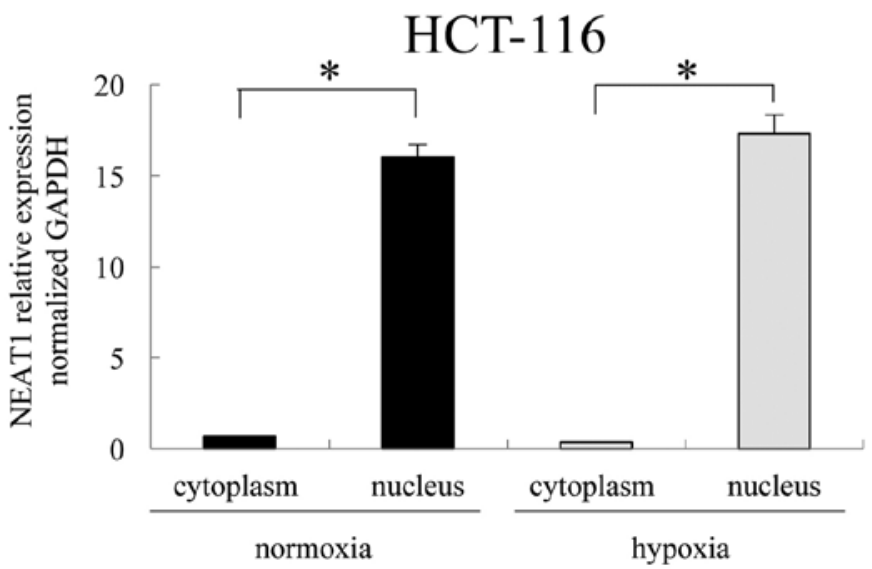

Figure 3. The long noncoding RNA (IncRNA) PCR array for nuclear or cytoplasmic fraction (A) Overview of lncRNA PCR array for nuclear or cytoplasmic fraction. The PARIS kit were used to separate the total cellular fractions into nuclear and cytoplasmic fractions. (B) Nuclear-enriched abundant transcript 1 (NEAT1) relative expression normalized glyceraldehyde 3-phosphate dehydrogenase (GAPDH) by qRT-PCR using each fraction of HCT-116 cells incubated under normoxic or hypoxic condition. ${ }^{*} \mathrm{P}<0.05$.

A

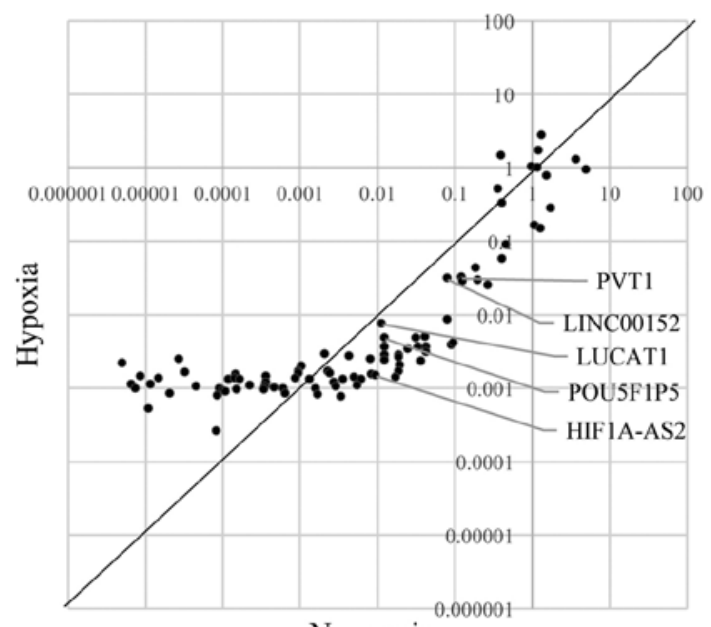

B

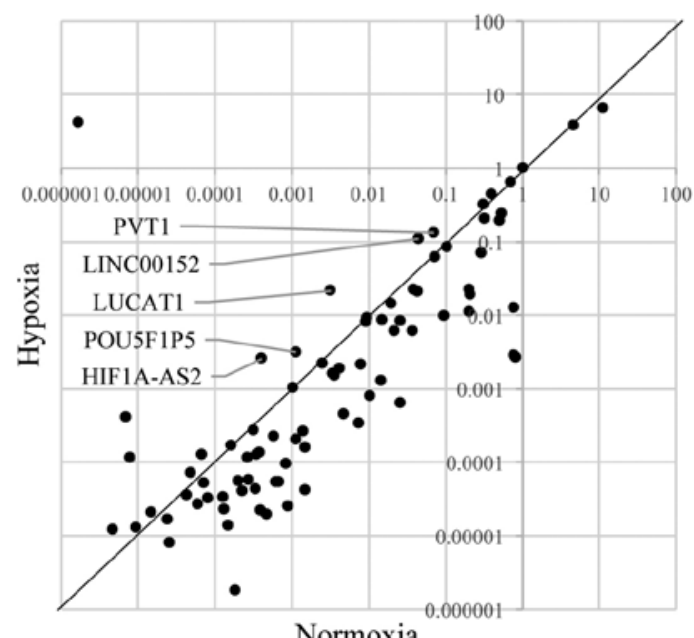

Figure 4. Scatter plots of the long noncoding RNA (lncRNA) PCR array. (A) Nuclear and (B) cytoplasmic fraction data. Each dot represents an lncRNA. The $\mathrm{x}$ - and $\mathrm{y}$-axes of the graphs show expression under normoxic and hypoxic condition, respectively. Five lncRNAs [plasmacytoma variant translocation 1 (PVT1), LINC00152, LUCAT1, POU5F1P5 and HIF1A-AS2] were upregulated in cytoplasm and downregulated in nucleus under hypoxia.

cytoplasm, we performed qRT-PCR using HCT-116 cells. The data showed that the expression levels of LUCAT1, POU5F1P5 and HIF1A-AS2 were lower than those of other IncRNAs (Fig. 5B). Thus, among the five lncRNAs, we focused on LINC00152 and PVT1. To study the significance of both LINC00152 and PVT1 in CRC patients, we used the TCGA database of colorectal adenocarcinoma (COADREAD). Data showed that both LINC00152 and PVT1 exhibited a higher level of expression in the tumor than in the normal tissue (Fig. 5C), and a high expression of LINC00152 was associated with a reduced overall survival rate $(\mathrm{P}=0.027)$ (Fig. 5D). 


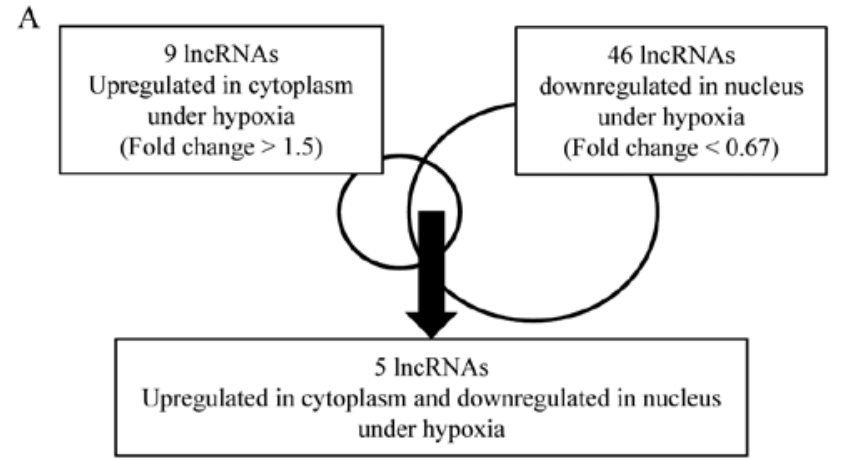

$\mathrm{C}$

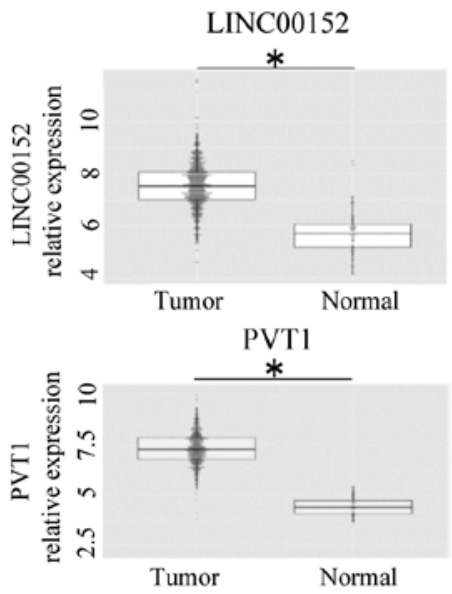

D

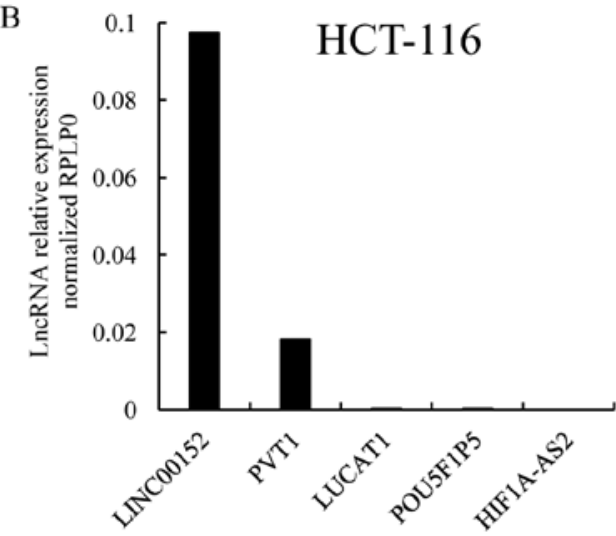

LINC00152

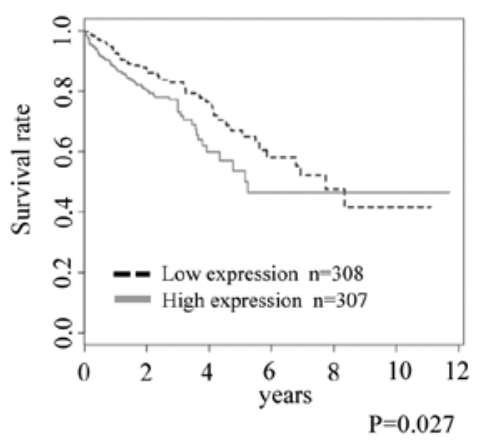

PVT1

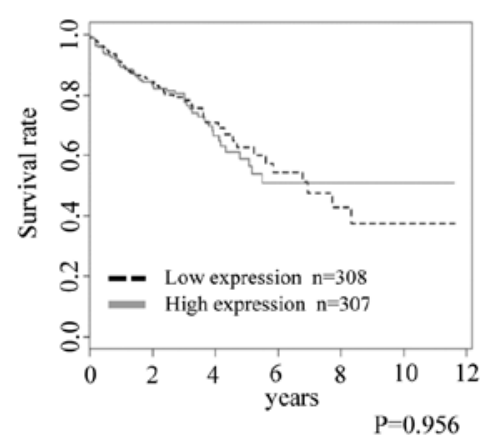

Figure 5. Long noncoding RNAs (IncRNAs) upregulated in the cytoplasm and downregulated in the nucleus under hypoxia. (A) Summary of lncRNA PCR array for each fraction. Nine lncRNAs upregulated in cytoplasm under hypoxia. Forty-six lncRNAs downregulated in nucleus under hypoxia. Five lncRNAs upregulated in cytoplasm and downregulated in nucleus under hypoxia. (B) Relative expressions of five lncRNAs normalized to RPLP0 by qRT-PCR. Among five lncRNAs, the expression levels of LINC00152 and plasmacytoma variant translocation 1 (PVT1) were higher than the other lncRNAs. (C) Relative expression of lncRNA using TCGA database (https://cancergenome.nih.gov/) of colorectal adenocarcinoma (COADREAD) for LINC00152 and PVT1. "P<0.001. (D) Kaplan-Meier curve of overall survival using TCGA database of colorectal adenocarcinoma (COADREAD). COADREAD database includes 615 CRC patient data. Survival curves were calculated using the Kaplan-Meier method and analyzed using the log-rank test.

\section{Discussion}

In this study, five types of IncRNAs exhibiting enhanced expression under hypoxic conditions showed decreased expression in the nucleus and increased expression in the cytoplasm. Based on the expression data, we focused on LINC00152, which has relatively high expression among the lncRNAs. LINC00152 is involved in cell growth, cycle arrest, epithelial-mesenchymal transition (EMT), and invasion in gastric cancers (19). Moreover, the plasma levels of LINC00152 achieve good diagnostic accuracy for $\mathrm{HCC}$ tumorigenesis and metastasis, and may act as novel biomarkers for HCC (20). Even in the data we examined in the TCGA database for patients with CRC (COADREAD), the expression of LINC00152 was more in tumors than in normal tissues, and the increased expression was associated with poor prognosis, which was consistent with a previous study (Fig. 5C and D). The present data are compatible with the notion that LINC00152 exhibits oncogenic function.

It is known that ceRNA binds miRNA in a nucleotide sequence-dependent manner and regulates miRNA as a decoy. Because this IncRNA-miRNA interaction occurs in the cytoplasm and most lncRNA is localized in the nucleus, we supposed that the hypoxia may induce the transformation of lncRNA function, so that it changes its localization from the nucleus to the cytoplasm in response to a hypoxic microenvironment.

Recently, it was reported that LINC00152 competes with miR-193a-3p as a ceRNA in colorectal cancers and is involved in the anticancer drug resistance to oxaliplatin (21). In addition, LINC00152 competes with miR-138 in gall bladder cancers, which suppresses HIF1A downstream of hypoxia pathway, thereby affecting cancer metastasis and EMT, which characterizes the metastasis of malignant cancer cells (22). The database study [miRcode; http://www.mircode.org; (23)] enabled us to identify the binding sites of not only previously reported miR-138 and miR-193 but also others, such as miR-150, miR-155, miR-31 and miR-205, as shared binding sites for LINC00152 and HIF1A, suggesting their ceRNA functionality. Thus, it was proposed that LINC00152 expression in the cytoplasm increases under hypoxic conditions and that it may act as a decoy for miRNAs involved in malignant cancers.

Previous studies indicated that the hypoxia inducible system is controlled by the post-translational modifications, as such involving Hif1 protein degradation $(2,3)$, in addition to our findings showing that LINC00152 is involved in the HIF1A mRNA translation by miRNA mechanism. Given that hypoxic condition induces the stabilization of Hif1 protein, 
which induces chemo-resistance and EMT pathway $(2,3)$, the present study indicates that the LINC00152 pathway collaborates with the post-translational pathway and enhances the tumor promoting function of Hif1.

Reportedly the study of a long non-coding antisense RNA affecting Uchl1 protein translation showed that rapamycin substantially increased antisense Uchll concentration in the cytoplasmic fraction and decreased antisense Uchl1 concentration in the nucleolar fraction, which correlates with the expression of Uchl1 protein, suggesting antisense Uchl1 localization can be regulated by the mTOR pathway (24). It is supposed that stress-dependent nucleocytoplasmic shuttling of lncRNAs may be a common strategy to regulate translation. Although these concepts need further clarification in future studies, we showed in the present study that the hypoxic condition induced the translocation of LINC00152 from nucleus to cytoplasm, and may function as ceRNA against miRNA, which targets HIF1A, and we supposed their relevance with the mTOR pathway (25).

Previously reported lncRNAs associated with CRC are shown in Table I. In this study using colon cancer cells, we identified five types of hypoxia-induced lncRNA which exhibit decreased expression in the nucleus and increased expression in the cytoplasm. It is suggested that LINC00152, which is related to various miRNAs, is associated with poor prognosis in patients with CRC. Further studies are necessary to identify useful biomarkers for the development of innovative therapeutic targets.

\section{Acknowledgements}

We thank the members of our laboratories for their helpful discussions. We thank Drs Tamura and Ikenaga for the careful arrangement of clinical samples; Dr Yamamoto, Division of Health Sciences, Osaka University, and Dr Takemasa, Department of Surgery, Sapporo Medical University, for fruitful discussions. This study was supported in part by a grant-in-aid for Scientific Research from the Ministry of Education, Culture, Sports, Science and Technology and Ministry of Health, Labor and Welfare; and by a grant from the National Institute of Biomedical Innovation and Osaka University Drug Discovery Funds. Institutional endowments were received partially from Taiho Pharmaceutical Co., Ltd., Evidence-Based Medical (EBM) Research Center, Idea Consultants, Inc. (Tokyo, Japan), and Kinshu-kai Medical Corporation (Osaka, Japan) [to Y.D., M.M. and H.I.]; Chugai Co., Ltd., Yakult Honsha Co., Ltd., and Merck Co., Ltd. [to Y.D., M.M. and T.S.]. These funders had no role in the main experimental equipment, supply expenses, study design, data collection and analysis, decision to publish, or preparation of the manuscript. This study received financial support from grants-in-aid for Scientific Research and P-DIRECT and P-CREATE grants from the Ministry of Education, Culture, Sports, Science and Technology, MEXT (to M.K., N.N., Y.D., M.M. and H.I.); Kobayashi Foundation for Cancer Research (to H.I.); Kobayashi International Scholarship Foundation (to M.K. and H.I.); a Grant-in-Aid from the Ministry of Health, Labor, and Welfare (to M.K., Y.D., M.M. and H.I.); and a Grant-in-Aid for Young Scientists (B) (Japan Society for the Promotion Science KAKENHI grant no. 17K16549) (to Y.N.).

\section{References}

1. Torre LA, Bray F, Siegel RL, Ferlay J, Lortet-Tieulent J and Jemal A: Global cancer statistics, 2012. CA Cancer J Clin 65: 87-108, 2015.

2. Hanahan D and Weinberg RA: The hallmarks of cancer. Cell 100: 57-70, 2000.

3. Hanahan D and Weinberg RA: Hallmarks of cancer: The next generation. Cell 144: 646-674, 2011.

4. Chen YG, Satpathy AT and Chang HY: Gene regulation in the immune system by long noncoding RNAs. Nat Immunol 18: 962-972, 2017.

5. Rinn JL, Kertesz M, Wang JK, Squazzo SL, Xu X, Brugmann SA, Goodnough LH, Helms JA, Farnham PJ, Segal E, et al: Functional demarcation of active and silent chromatin domains in human HOX loci by noncoding RNAs. Cell 129: 1311-1323, 2007.

6. Wu L, Zhang L and Zheng S: Role of the long non-coding RNA HOTAIR in hepatocellular carcinoma. Oncol Lett 14: 1233-1239, 2017.

7. Bhan A, Soleimani M and Mandal SS: Long noncoding RNA and cancer: A New Paradigm. Cancer Res 77: 3965-3981, 2017.

8. Dong J, Su M, Chang W, Zhang K, Wu S and Xu T: Long non-coding RNAs on the stage of cervical cancer (Review). Oncol Rep 38: 1923-1931, 2017.

9. Lu D, Luo P, Wang Q, Ye Y and Wang B: lncRNA PVT1 in cancer: A review and meta-analysis. Clin Chim Acta 474: 1-7, 2017.

10. Yoon JH, Kim J and Gorospe M: Long noncoding RNA turnover. Biochimie 117: 15-21, 2015.

11. Yu B and Shan G: Functions of long noncoding RNAs in the nucleus. Nucleus 7: 155-166, 2016.

12. An Y, Furber KL and Ji S: Pseudogenes regulate parental gene expression via ceRNA network. J Cell Mol Med 21: 185-192, 2017.

13. Robertson ED, Semenchenko K and Wasylyk B: Crosstalk between Mdm2, p53 and HIF1 $\alpha$ : Distinct responses to oxygen stress and implications for tumour hypoxia. Subcell Biochem 85: 199-214, 2014.

14. Fan C, Tang Y, Wang J, Xiong F, Guo C, Wang Y, Zhang S, Gong Z, Wei F, Yang L, et al: Role of long non-coding RNAs in glucose metabolism in cancer. Mol Cancer 16: 130, 2017.

15. Sugimura K, Fujiwara Y, Omori T, Motoori M, Miyoshi N, Akita H, Gotoh K, Kobayashi S, Takahashi H, Noura S, et al: Clinical importance of a transcription reverse-transcription concerted (TRC) diagnosis using peritoneal lavage fluids obtained pre- and post-lymphadenectomy from gastric cancer patients. Surg Today 46: 654-660, 2016.

16. Livak KJ and Schmittgen TD: Analysis of relative gene expression data using real-time quantitative PCR and the 2(-Delta Delta C(T)) method. Methods 25: 402-408, 2001.

17. Wykoff CC, Beasley NJ, Watson PH, Turner KJ, Pastorek J, Sibtain A, Wilson GD, Turley H, Talks KL, Maxwell PH, et al: Hypoxia-inducible expression of tumor-associated carbonic anhydrases. Cancer Res 60: 7075-7083, 2000.

18. Chang YN, Zhang K, Hu ZM, Qi HX, Shi ZM, Han XH, Han YW and Hong W: Hypoxia-regulated lncRNAs in cancer. Gene 575: $1-8,2016$.

19. Zhao J, Liu Y, Zhang W, Zhou Z, Wu J, Cui P, Zhang Y and Huang G: Long non-coding RNA Linc00152 is involved in cell cycle arrest, apoptosis, epithelial to mesenchymal transition, cell migration and invasion in gastric cancer. Cell Cycle 14: 3112-3123, 2015.

20. Li J, Wang X, Tang J, Jiang R, Zhang W, Ji J and Sun B: HULC and Linc00152 act as novel biomarkers in predicting diagnosis of hepatocellular carcinoma. Cell Physiol Biochem 37: 687-696, 2015.

21. Yue B, Cai D, Liu C, Fang C and Yan D: Linc00152 functions as a competing endogenous RNA to confer oxaliplatin resistance and holds prognostic values in colon cancer. Mol Ther 24: 2064-2077, 2016.

22. Cai Q, Wang Z, Wang S, Weng M, Zhou D, Li C, Wang J, Chen E and Quan Z: Long non-coding RNA LINC00152 promotes gallbladder cancer metastasis and epithelial-mesenchymal transition by regulating HIF-1 $\alpha$ via miR-138. Open Biol 7: 160247, 2017.

23. Jeggari A, Marks DS and Larsson E: miRcode: A map of putative microRNA target sites in the long non-coding transcriptome. Bioinformatics 28: 2062-2063, 2012.

24. Carrieri C, Cimatti L, Biagioli M, Beugnet A, Zucchelli S, Fedele S, Pesce E, Ferrer I, Collavin L, Santoro C, et al: Long non-coding antisense RNA controls Uchl1 translation through an embedded SINEB2 repeat. Nature 491: 454-457, 2012. 
25. Salmena L, Poliseno L, Tay Y, Kats L and Pandolfi PP: A ceRNA hypothesis: The Rosetta Stone of a hidden RNA language? Cell 146: 353-358, 2011.

26. Li L, Zhang GQ, Chen H, Zhao ZJ, Chen HZ, Liu H, Wang G, Jia YH, Pan SH, Kong R, et al: Plasma and tumor levels of Linc-pint are diagnostic and prognostic biomarkers for pancreatic cancer. Oncotarget 7: 71773-71781, 2016.

27. Li N and Richard S: Sam68 functions as a transcriptional coactivator of the p53 tumor suppressor. Nucleic Acids Res 44: 8726-8741, 2016.

28. Kan JY, Wu DC, Yu FJ, Wu CY, Ho YW, Chiu YJ, Jian SF, Hung JY, Wang JY and Kuo PL: Chemokine (C-C Motif) Ligand 5 is Involved in tumor-associated dendritic cell-mediated colon cancer progression through non-coding RNA MALAT-1. J Cell Physiol 230: 1883-1894, 2015.
29. Zhang R, Guo Y, Ma Z, Ma G, Xue Q, Li F and Liu L: Long non-coding RNA PTENP1 functions as a ceRNA to modulate PTEN level by decoying miR-106b and miR-93 in gastric cancer. Oncotarget 8: 26079-26089, 2017.

30. Ling H, Spizzo R, Atlasi Y, Nicoloso M, Shimizu M, Redis RS Nishida N, Gafà R, Song J, Guo Z, et al: CCAT2, a novel noncoding RNA mapping to $8 \mathrm{q} 24$, underlies metastatic progression and chromosomal instability in colon cancer. Genome Res 23: 1446-1461, 2013.

31. Luo ZF, Zhao D, Li XQ, Cui YX, Ma N, Lu CX, Liu MY and Zhou Y: Clinical significance of HOTAIR expression in colon cancer. World J Gastroenterol 22: 5254-5259, 2016. 